\title{
Living with AAR: An Engineer's Perspective
}

\author{
Jonathan $G M \mathrm{Wood}^{1, *}$ \\ ${ }^{1}$ Director, Structural Studies \& Design Ltd. Chiddingfold UK
}

\begin{abstract}
In the 1980s some unexpected cases of AAR cracking developed in the UK. There was no guidance on its effects on structures. In Devon many bridges, a car park and the 400 bed Exeter hospital had severe cracking and it was growing. Innovations in testing and analysis on these structures and their concrete led to the development of the IStructE Guidance on Structural Effects of AAR. The severity of damage to the hospital led to its replacement. Other buildings and bridges throughout the UK have benefited from this engineering approach to their management. It has provided a basis for RILEM international guidance. Expansion to date can be determined from surface cracking or loss of stiffness of cores. Well detailed reinforcement, to contain expansion in 3 dimensions, retains strength. Cracking leading to failure can develop where there is no reinforcement aligned to contain it. Petrography can diagnose AAR, even when it is trivial, but cannot quantify its severity. Most structures can live safely with an AAR diagnosis, but the containment provided by the reinforcement must be checked and augmented if necessary. Controlling moisture can slow the reaction, but this is not possible below ground where the worst problems occur.
\end{abstract}

\section{Introduction}

Alkali Aggregate Reaction (AAR or ASR) is widespread, but usually insignificant. Some aggregates can react with the alkali from cement to slowly form silica gel which absorbs water and swells. Only when there is plenty of alkali and sufficient reactive aggregates with some water will it, in the long term, expand to crack concrete and to yield reinforcement. For general UK construction the recommendation is to keep mix alkali content below $3 \mathrm{~kg} \mathrm{NaOH}$ eq $/ \mathrm{m}^{3}$. The worst Devon cases had 5 to $7 \mathrm{~kg} \mathrm{NaOH}$ eq $/ \mathrm{m}^{3}$ from using $500 \mathrm{~kg} / \mathrm{m}^{3}$ of cement with 1.2 to $1.4 \% \mathrm{NaOH}_{\text {eq }}$.

Most literature on AAR focuses on the concrete, but the consequences for structures largely depend on the reinforcement and moisture available. The engineering perspective has to focus on these two aspects.

Cracking is the first indication of significant AAR expansion, but all concrete cracks. The defining characteristic of AAR cracking is that it slowly grows year by year. Typically, it is only reported after 5 to 10 years when some reach 1 to $2 \mathrm{~mm}$ width. In contrast cracking from restraint of shrinkage and thermal changes develops within a year.

The literature talks of 'Map' cracking, a random net of cracks, Fig 1 . This only occurs when the concrete is lightly stressed and unrestrained by reinforcement, e.g. in dams. Restraint and compression orientate cracking, so columns crack predominately vertically and beams crack predominantly longitudinally in bridges. Pop outs over aggregates and gel exudation have been reported, but are specific to a few aggregates. On large structures, particularly dams, overall expansion may close joints or disrupt machinery to indicate expansion.

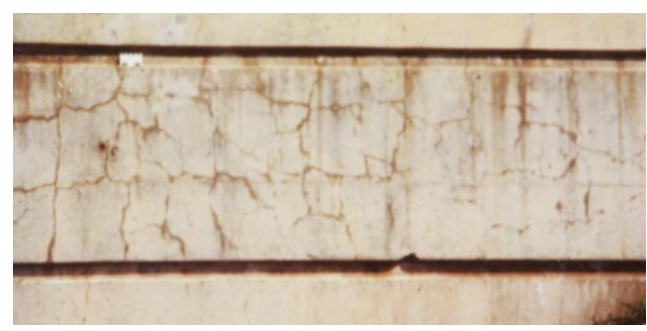

Fig.1 Classic AAR 'Map' cracking

In the early 1970s increases in some cement alkali contents, higher cement contents in mixes and new aggregate sources led to two extensive areas of structures with serious damage in Devon and the Midlands, with isolated cases elsewhere. There was some knowledge of the reaction at laboratory scale with some aggregate types, but little was known about how the expansion and cracking effected the strength and stability of the bridges and buildings in which it was developing.

The 1983 6th ICAAR conference in Copenhagen facilitated international dialog. There was information on the mineralogy of some reacting aggregates, the influence of cement alkalinity and accelerated testing of small mortar bars. There were descriptions of damaged dams and bridges. However, there was little information on:

- how long the reaction took to develop in the field?

* Corresponding author: jonathan@ss-design.demon.co.uk 
- how the expansion characteristics varied with different aggregate sources?

- how to test samples from structures to establish the changed anisotropic strength and stiffness resulting from the expansion?

- how the reinforcement and structural stresses modified and contained expansion and cracking?

- how to test cores to establish the potential for future expansion?

Theories abounded, but data was scarce in the 1980s.

The scale and severity of the damage developing in the UK justified monitoring and the development of testing of comprehensive sets of samples from a wide range of structures to provide data for structural appraisal. This led to the 1992 IStructE guidance 'Structural Effects of ASR' [1][2]. These recommendations, updated in 2010, are a well proven basis for assessing bridges and buildings.

Most UK structures in which AAR has been diagnosed have slight localised cracking from low levels of expansion which is sufficiently contained by reinforcement. For others, measures to limit moisture availability and local strengthening of critical parts have been necessary. However, the worst examples have eventually necessitated demolition and replacement, as summarised in the case history section below.

Since then international cooperation and research and data from testing and monitoring structures being damaged by AAR has provided improved guidance on both specifying to avoid AAR and the appraisal and management of structures being damaged by AAR. RILEM provides the focus for this and recent publications [3] make the still developing state of the art accessible. Sims [4] has updated the review of worldwide cases of AAR. The proceedings of the 15 ICAAR conferences up to 2016 worldwide provide an outstanding record of case histories and research.

\section{Investigating structures with unusual cracks and movements}

An engineer's responsibility is for the performance and safety of the structure overall. For a bridge one must minimise disruption to traffic; in a hospital prevent disruption of doctors and patients; on a dam ensure that power generation and flood control are not at risk and in a shopping centre one must not interrupt the footfall of shoppers. These considerations are a high priority when planning access and costs of investigating suspect AAR and when planning remedial works.

Reviewing available drawings and specifications, construction records and reports of regular inspections is an essential first step before inspecting a structure. Interviewing those who built and operated the structure is important as anecdotal data on mix supplies and changes can be useful. Many individuals will have survived longer than the written records of design and construction!

Often structures suffer from a range of interacting deterioration process including corrosion and frost damage. Inadequacies of the original design standards, bad detailing and faulty construction not infrequently become apparent and can be more important than AAR in the management of the structures and any remedial work.

Investigations need to obtain the maximum information during short periods of access. This needs to be considered in planning inspection, sampling, and monitoring. Coring to obtain sufficient representative concrete samples for physical, petrographic and chemical testing can be most disruptive. It must to be carried out with precision to avoid cutting reinforcement, which can cause more damage than AAR.

Concrete and expansive reactions are inherently variable within and between pours, due to random variations in cement contents, reactive aggregate proportions, availability of moisture and temperature. A sufficiently representative range of cores will be needed. It is the variability of expansions within and between adjacent pours that creates the cracking and damage.

Expansions will be restrained by compressive stresses created by normal structural action and/or the restraint of expansion by the reinforcement. Tensile stress increases expansion and cracking. It is not that simple, as one needs to consider the 3-dimensional stresses. In a column axial compression limits horizontal cracking but increases lateral expansions, which are only lightly resisted by stirrups, so vertical cracks form.

\section{Preliminary inspection and sampling}

Preliminary inspection and sampling needs to be a joint operation by materials specialists and engineers to collect samples which will be subdivided for diagnosis and structural appraisal. The detailed recommendations, including those for coring concrete for samples and recording cracking in selected representative areas, are comprehensively set out by Godart [5].

This also covers diagnosis of AAR using petrography. Additional engineering inspections, coring and installation of monitoring may be required if a risk of significant structural damage is found during appraisal.

Before starting to inspect, record cracks and take sample cores from a structure, it is best to understand the stresses and normal cracking to be expected during construction and subsequent shrinkage. High cement contents increase the risk of AAR, but they also create more initial heat, a risk of DEF and increased shrinkage, all of which contribute to cracking. These effects will interact. AAR cracking may only become the dominant cause of cracking after 10 years or more.

Estimates should be made, for dead load and live load conditions, of the approximate magnitude and orientation of compressive, shear and tensile stress, which will supress or increase AAR cracking.

For normal concrete, cracking up to $0.3 \mathrm{~mm}$ is deemed acceptable. With severe AAR cracks 1 to $2 \mathrm{~mm}$ wide develop over 10 to 20 years. When there is no change in the availability of water, AAR cracks increase 
in width at a broadly consistent annual rate [6] when monitored over decades, Fig 2.



Fig.2. Typical crack growth over 18 years.

The quantification of cracking as a measure of expansion to date and expansion rate is discussed below.

As an engineer the key questions to the petrographer, which should be discussed directly with him after considering his initial report include:

- Is this a known type of AAR reactive mix and are there similar structures which may have been tested and monitored or should be?

- Has a check been made to see if current specifications rule out this reactive cement and aggregate combination in future construction?

- What is the cement type and content so that initial heat rise and shrinkage can be estimated so their contributions to cracking can be estimated?

- Are there other features indicative of concrete deterioration?

- Is there evidence of delamination cracking in the plane of the reinforcement?

\section{Engineering testing of cores}

With normal concrete a standard compression test on a short core $(\mathrm{h} / \mathrm{d} \approx 1)$ gives a crushing strength from which stresses and strength can be calculated conventionally. Tensile strength and Young's modulus (E) are implicit in the simplified formulae in the concrete codes.

With concrete developing AAR all those relationships are invalidated. The microcracking which develops reduces tensile strength. In a short core compression test the platen friction prevents splitting and failure. To measure the uniaxial compressive strength the core needs to have $\mathrm{h} / \mathrm{d} \approx 2.5$. Direct measurement of tensile strength is difficult with normal concrete and AAR complicates things [7].

Concrete with AAR becomes anisotropic in a stress field, with microcracks growing in tensile or unconstrained directions and suppressed by compression. Preventing the microcracks growing into structural fractures where inadequately restrained by reinforcement in 3-D is the key challenge in assessment and remedial work. The concrete develops a 'grain' and weak planes like timber!
Table 1 Lower bound residual mechanical properties as percentage of values for unaffected concrete [1].

\begin{tabular}{llllll} 
Free expansion $\mathrm{mm} / \mathrm{m}$ & 0.5 & 1.0 & 2.5 & 5.0 & 10.0 \\
\hline Compression $\mathrm{h} / \mathrm{d} \approx 1$ & 100 & 85 & 80 & 75 & 70 \\
Uniaxial compression & 95 & 80 & 60 & 60 & - \\
Tension & 85 & 75 & 55 & 40 & - \\
Elastic modulus E & 100 & 70 & 50 & 35 & 30
\end{tabular}

The microcracking of concrete with AAR results in a loss of stiffness as the stress strain curve changes from linear elastic to loops as hysteresis develops when stress is cycled.

The Stiffness Damage Test (SDT) quantifies the microcracking in the test length of the core. With sensitive equipment this is quite clear with a stress range of 0.5 to $5.5 \mathrm{MPa}$, so damage to the core is minimised. It can be used to sort all cores prior to further testing for strength, expansion or petrography.

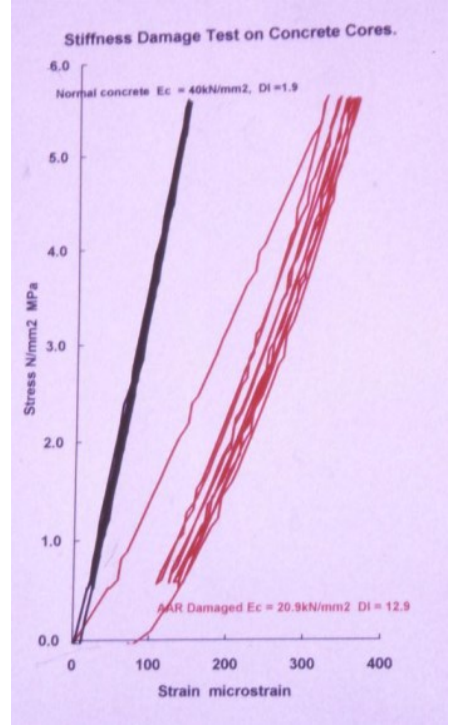

Fig 3a. SDT Plots Normal and AAR

The original research procedures of Crouch [8] and Crisp [9] examined a range of parameters. More recently researchers have unnecessarily elaborated the procedure and adopted higher stress ranges which invalidate the original purpose of STD as a non-damaging precursor to a range of tests.

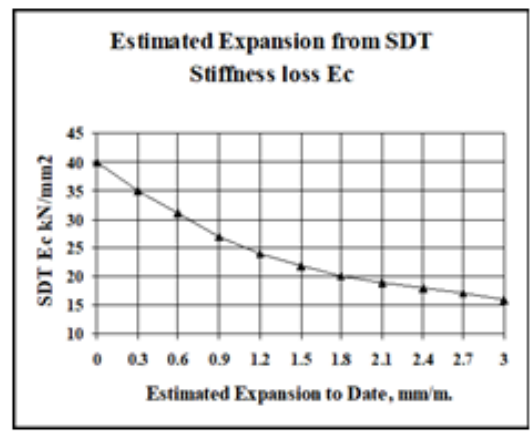

Figure $3 b$ Estimated expansion from SDT 
Results from all sources [10] confirm the broad relationships of petrographically observed microcracking, stiffness loss and development of hysteresis with the expansion to date, but further calibration on a range of site concretes would be beneficial.

The engineering simplification, adopted in evaluating 100 s of cores from more than 20 UK structures, is to take the rising slope of the 3 rd cycle to determine an ' $\mathrm{E}_{3}$ ', as a measure of microcracking from which the expansion to date of that core can be estimated. It is a complementary procedure to crack summation.

SDT is helpful when surface cracking cannot be surveyed easily, e.g. in foundations, and in flat slabs where the heavy flexural reinforcement limits cracking and internal microcracking needs to be checked to assess shear strength, risk of delamination and loss of bond to reinforcement.

\section{$5 \quad$ Modelling}

Predictive modelling of structural behaviour is a challenging objective for assessment. Developing anisotropy, with strains no longer determined by stress as expansion develops and with the random variability of expansions in the concrete, make it hard to relate detailed modelling of concrete behaviour to reality.

Fortunately, concrete cracks when tensile strains exceed about $0.2 \mathrm{~mm} / \mathrm{m}$. So careful examination of the cracking on a structure will show, without a computer, where surface tensile strains are greater than $0.2 \mathrm{~mm} / \mathrm{m}$. The orientation of cracks shows the direction of tensile stress.

By measuring crack width crossing survey lines normal and parallel to the predominant cracks, a series of estimates of 'Expansion $=$ (Sum of crack widths/ line length)' can be made. Cracks due to restrained shrinkage and thermal movement etc. need to be discounted [11]. Where underlying reinforcement or compression is suppressing cracking, this must be adjusted for. This, together with the data from SDT, will give an estimate of the average free expansion to date in a structural member.

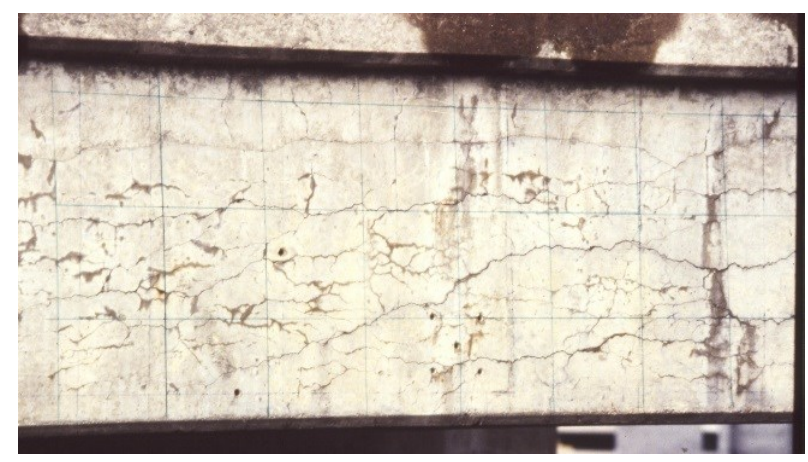

Fig 4. Beam with cracks predominantly parallel to main reinforcement marked for crack summation. Well detailed 3-D reinforcement cage maintained the safety of this beam.

If a conventional FE model in 3-D is made of the reinforcement and the concrete, it can be tweaked to represent the average AAR expansive strain by inputting a raised concrete temperature relative to the steel, Fig 5. This will show up areas of compression where microcracking will be suppressed and expansion reduced, tensile areas where microcracks can potentially grow into fractures and the additional stress and strain in the steel. With low steel areas (e.g. stirrups in a beam) AAR can yield the reinforcement, which is not a problem if it is ductile and well anchored.

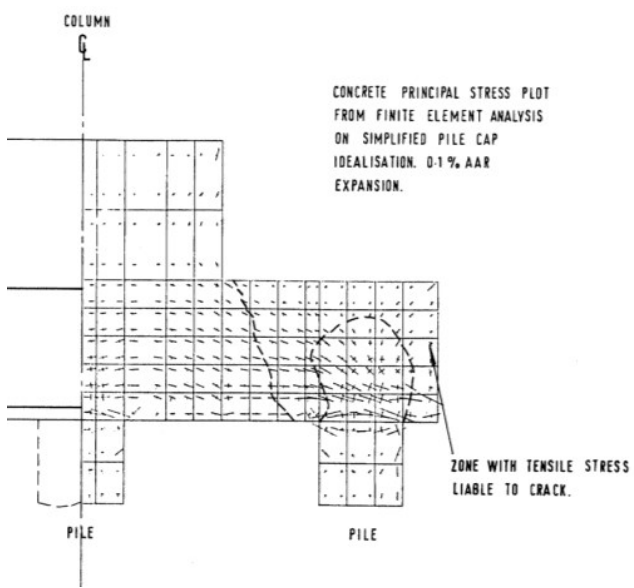

Fig $5.1 \mathrm{~mm} / \mathrm{m}$ expansion, as temperature differential concrete to steel. Marsh Mills pile caps.

The weak links in the structure show up where high bond stresses develop on the ends of reinforcement without hooks and where reinforcement does not provide full 3-D constraint. Bond failure between reinforcement and concrete, delamination where microcracking develops under reinforcement mesh are high risk areas when expansions exceed $1.0 \mathrm{~mm} / \mathrm{m}$.

In unreinforced mass concrete cracking will develop randomly, but it may still work as a 'dry stone wall'. Unreinforced pad foundations are high risk.

\section{Further Expansion}

The potential for further expansion can be estimated from monitoring the rate of growth of cracks or overall dimensions. With the very slow rate of development of AAR this takes years, Fig 2. However, as the reaction and damage development is slow there is time to monitor. A preliminary estimate can be based on widespread experience that the crack widths (and expansion) will no more than double by the time the structure's age doubles.

Expansion testing of cores with consistent availability of moisture will provide data on the potential for and rate of further expansion and importantly the variability of expansion within cores, within pours and various concrete pours.

The literature is full of examples where test expansions have stopped as alkali has leached from samples. Storage of individual cores with limited water in sealed containers, Fig 6, is reliable and cheaper then elaborate erratic "High" humidity procedures. The relationship of water absorbed to expansion can be recorded. Testing at laboratory temperature $20^{\circ} \mathrm{C}+/-$ 
$3^{0} \mathrm{C}$ gives expansions ten times faster than in the field (UK). $38^{\circ} \mathrm{C}$ testing is more complex, but faster for diagnosis.



Fig 6. Water supply expansion test container. No Alkali leaching, water kept to $10 \mathrm{~g} / \mathrm{kg}$. Core weight change recorded.

Demec or similar measures of expansion on typically 3 rows of 2 gauge lengths shows up the variability of expansion. Low cost enables the variability of pours to be quantified by testing dozens of cores.

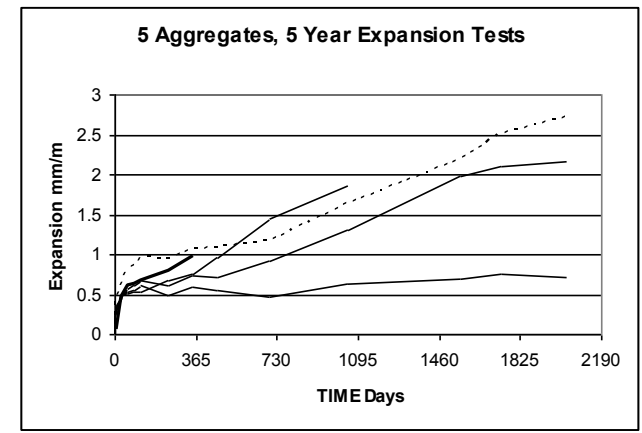

Fig 7. Variation in expansion within typical core

For engineering assessment, it is better to have a large range of samples tested cost effectively with reasonable precision rather than a few samples tested elaborately. It is also best to tailor testing to the specific structural questions rather than using inappropriate standard tests.

Along with petrography, expansion tests enable those parts of the structure which will be stable or very slow expanding to be identified. Reasons include lower cement contents, differing aggregate sources and cements and remotely sourced precast elements. Sometimes the greatest problems arise at the interface between reacting and non-reacting elements.

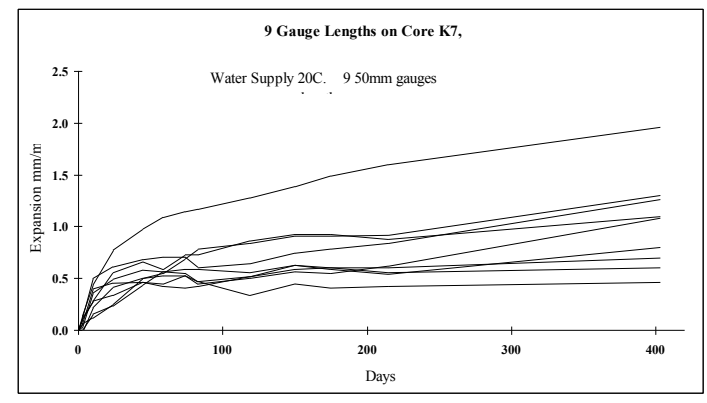

Fig 8. Variation in long term expansion, 5 aggregates.

\section{Structural Severity Rating}

The IStructE 'Structural Severity Rating' of structural elements is based on determining:

- The magnitude of expansion to date and the potential for further expansion.

- The extent to which the reinforcement and stresses in the structure limit expansion and control the development of structural cracking.

- The potential consequences of failure.

- The availability of moisture to develop the reaction and the extent to which this can be controlled.

- The level of stresses and factor of safety in the element to provide a reserve of strength for deterioration.

By assessing each structural element, the most sensitive elements can be identified. They can then be further tested, monitored, strengthened and/or protected from moisture as appropriate. For the majority of structures with good reinforcement and $\leq 0.6 \mathrm{~mm} / \mathrm{m}$ expansion no further actions, other than routine inspections and upgrading of water shedding, are needed.

\section{Case studies}

The principles for assessment and management of structures with AAR outlined above and more fully in papers $[12][13][14]$ have guided investigations, monitoring, remedials and management of a wide range of structures Brief key details are summarised as case studies.

Charles Cross Car Park in Plymouth built in 1970 with $500 \mathrm{~kg} / \mathrm{m}^{3}, 1.2$ to $1.4 \mathrm{NaOH}$ cement and sea dredged fines with reactive chert ( 2 to $5 \mathrm{~mm}$ ) with inert coarse aggregate was the first significant case of AAR in UK. The severity of the cracking, with little knowledge of its structural effects, justified pre-emptive strengthening duplicating much of the main frame but retaining the parking slabs. Re-assessment showed much of the structure to have robust 3-D reinforcement cages to contain cracking. With monitoring and some proof loading it was retained in service until demolition in May 2004 as part of a retail and parking re-development of the area.

A38 Bridges between Exeter and Plymouth were built in $1970-72$ wholly or in part with similar reactive concrete to that at Charles Cross.

Voss Farm Bridge had mostly highly reactive elements. Badly cracked and delaminating foundations and three columns were monitored and then replaced with a new foundation slab over the old. The four new columns supported the non reactive deck so that the three old columns could be removed. They were left exposed for long term monitoring off site. Delaminating wing walls and abutments were reinforced. 




Fig. 9. Table of the Structural Severity Rating of elements of a small bridge with AAR.

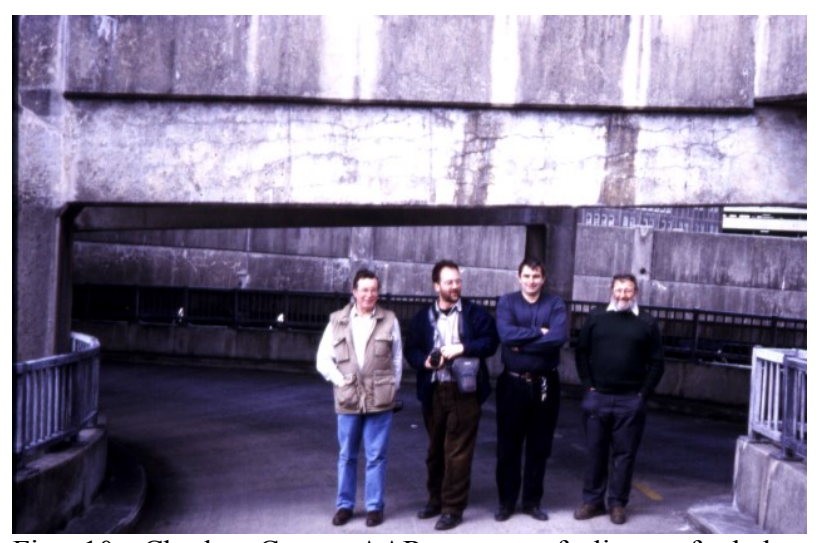

Fig. 10. Charles Cross. AAR experts feeling safe below severely cracked well reinforced beam

Marsh Mills viaducts 410m long, each with 3 lanes over $1330 \mathrm{~m}$ spans were supported on prestressed precast beams which were parting company from the insitu reactive concrete slab and diaphragms at piers. The reactive narrow piers with wide crossheads were supported on wide $1.5 \mathrm{~m}$ deep reactive delaminating pile caps. Reducing pile cap shears by propping directly up to under the crossheads and reducing traffic to two lanes enabled the viaduct to be kept in service until in 1992, when new one piece $410 \mathrm{~m}$ long bridges were slid across into place.



Figure 11. Marsh Mills pile cap split and delaminated by AAR.

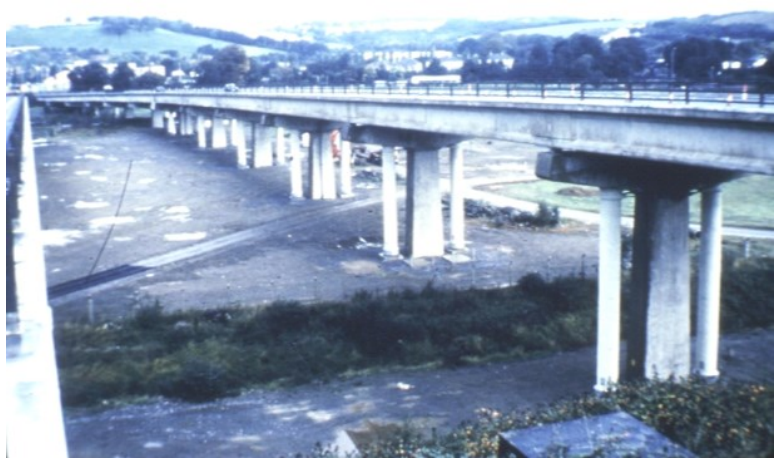

Figure 12 Propping of Marsh Mills Viaduct.

Five storey office building in the NW was built c1970 using precast wall panels, incorporating windows, to support the floor slabs. For aesthetic reasons $4 \%$ glass was incorporated in the mix for these units. This reacted and slight cracking progressively widened to weaken a growing proportion of the units. It was monitored but eventually the impracticality of remedial work led in 2001 to demolition and redevelopment, as its condition was unacceptable to tenants.

RD\&E Hospital, a major regional 400 bed hospital, was built in c1970 mostly with the same highly reactive mix as Charles Cross. Initial diagnosis, following widespread cracking of the exposed concrete, was followed by examination of the foundations where more severe cracking was found in foundation pads without reinforcement. In larger deeper reinforced pad foundations under the tower the concrete was found to be delaminating from the reinforcement.

The paramount need to minimise disruption to health care led to a strategy of closely monitoring the development of the reaction and for any foundation movement while a new hospital was built alongside. This opened between 1992 and 1996 allowing the old buildings to be demolished. 


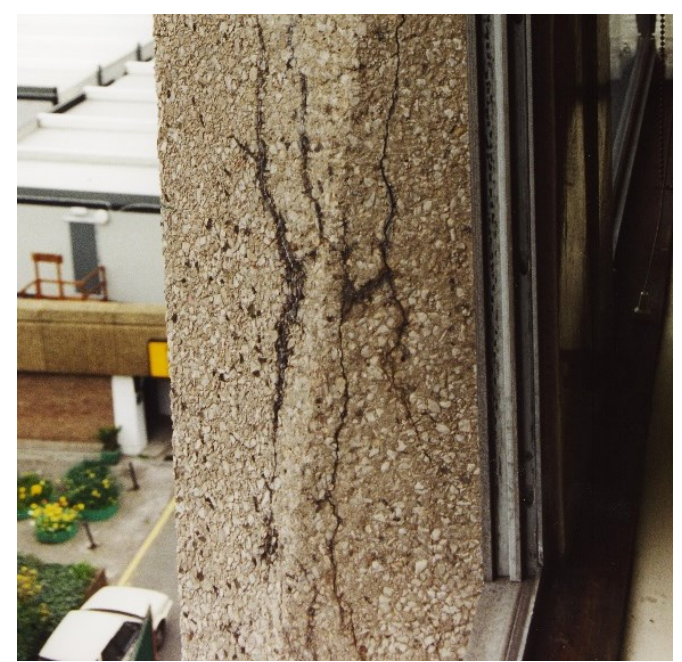

Fig 13. Cracking of precast panels with reactive glass.

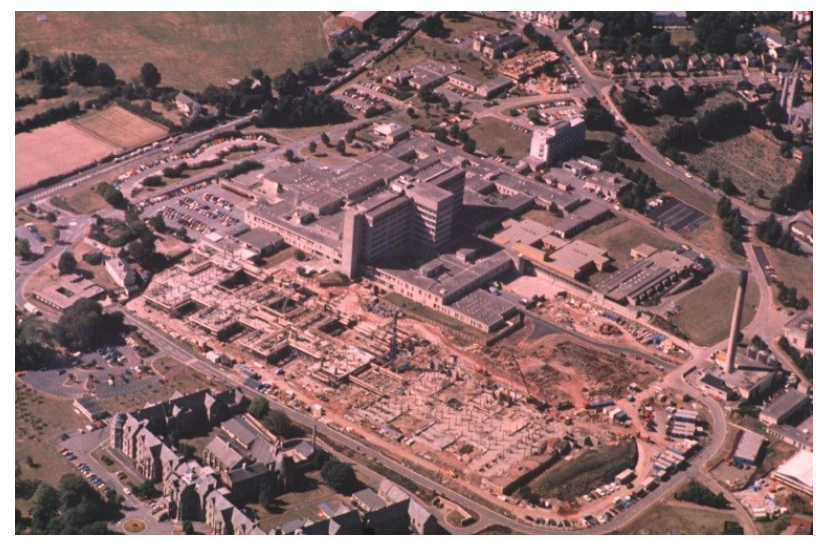

Fig. 14. New RD\&E Hospital being built in foreground with monitored AAR damaged 1970 hospital behind

Smorrall Lane Some 50 bridges on the Warwickshire stretch of M6 motorway were constructed using a reactive aggregate. Mostly they were of $30 \mathrm{~m}$ span, but at a service area the standard in-situ beam and slab design was extended for $45 \mathrm{~m}$ spans. For this, 4 layers of straight $50 \mathrm{~mm}$ diameter bars, without bends or hooks for anchorage, were used. This congestion of steel necessitated crushing the aggregate from $20 \mathrm{~mm}$ to $\leq$ $10 \mathrm{~mm}$, increasing the reactivity of quartzite, with increased cement content to achieve workability. This produced significantly more reactivity and expansion $(2+$ $\mathrm{mm} / \mathrm{m}$ ) compared to about $0.6 \mathrm{~mm} / \mathrm{m}$ on the other bridges where it was not significant.

Because the M6 is a strategic route uncertainty and ongoing disruption were unacceptable. Each span was cut, lifted out and replace during a planned 3 week carriageway resurfacing closure. The lifted out beams were stored nearby for some years for monitoring as cracking further developed.

Montrose Bridge [15] was an important early 1930s concrete of faux 'suspension bridge' form on the main East coast road Edinburgh to Aberdeen.

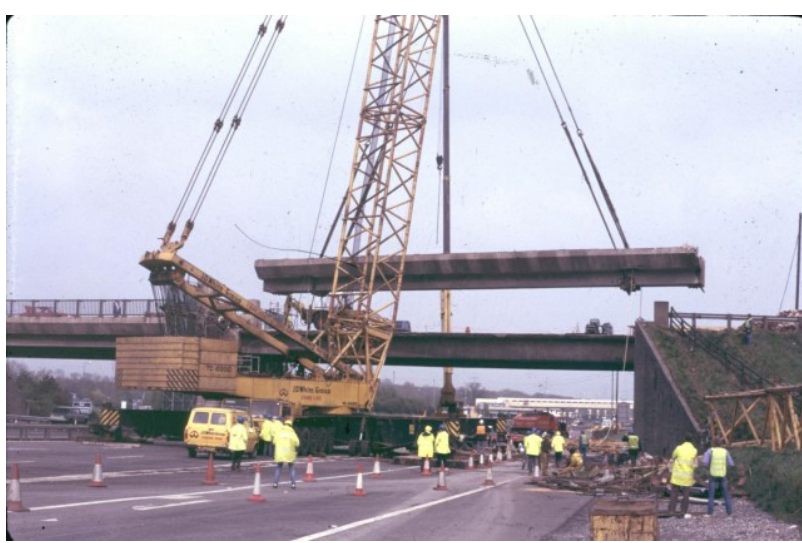

Fig. 15 Lifting out 600t beam from Smorall Lane Bridge.

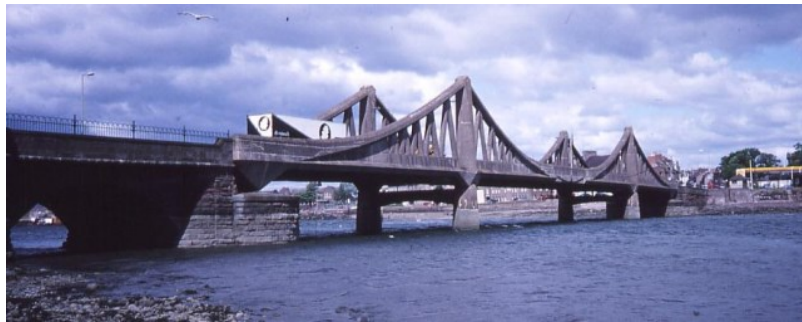

Fig 16 Montrose Bridge 1930.

The Scottish cement was low alkali, but for a prestige structure a high alkali English cement was used and this very slowly reacted with the rhyolite. The progressive development of cracks was recorded periodically, but was undiagnosed until the 1970s. Injected cracks merely re-cracked.

A full IStructE type investigation in the 1990s confirmed AAR and identified that the worst cracking of the tower tops where the main reinforcement was not contained at the saddle and could fail. Precision drilling and plating with covers to stop water ingress restored the safety of the bridge. However, the deck slab was progressively deteriorating from salt induced corrosion, AAR, frost damage and wheel loads delaminating the deck slab. The bridge was lifted out and replaced in 2005.

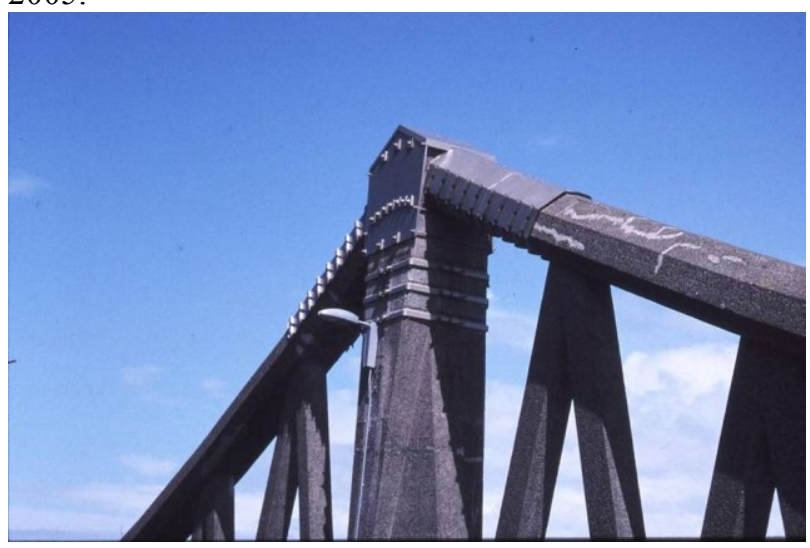

Fig 17. Montrose Bridge. Plated and clamped to prevent splitting. Covers to restrict water ingress. 

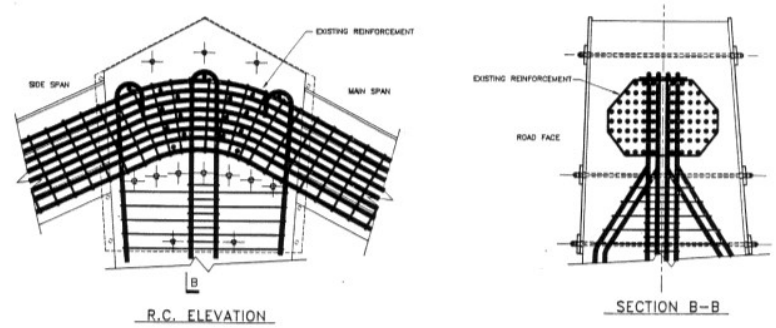

Fig 18. Montrose Bridge. Plated and clamped to prevent splitting. Showing main 'Cable' reinforcement originally uncontained.

Industrial Tower. A listed redundant landmark industrial tower, 127.5 metres (418 ft) tall, was built in 1982. A developer bought the site for housing in 1999 and then claimed that AAR justified demolition of tower. There was slight but distinctive AAR cracking but only in well reinforced base. Petrographic checks showed some indications of AAR. Permission was refused as AAR was not significant. It is now refurbished and used for industrial testing and as an abseiling centre.

\section{Conclusion}

Major challenges for research on understanding and predicting AAR behaviour remain. We need:

- More data from field testing and monitoring of mature structures.

- Records of the time scale of the reaction and cracking in the field and the influence of varying temperatures and moisture availability.

- Quantification of the inherent variability of the reaction and expansions.

- Developing modelling of the reaction and its structural effects calibrated against large scale laboratory test and field data.

Many helped with this work. My thanks to my former colleagues at Mott Hay and Anderson, Philip Nixon and BRE, Chris Page, Bruno Godart and all my other friends worldwide who have helped in starting to unravel the secrets of AAR.

\section{References}

1. IStructE. 'Structural Effects of ASR, Appraisal of Existing Structures'. London. SETO London, (1992). Addenda (2010).

2. J G M Wood \& R A Johnson, 'The Appraisal and Maintenance of Structures with Alkali Silica Reaction.' Structural Engineer 71, 2 pp 19-23, (1993)

3. Proc. ICE - Construction Materials, Issue 3: Themed issue on alkali-aggregate reactions: part I (June, pp. 117-178). Issue 4: part II (August, pp. 179-237). (2016)

4 I Sims, A B Poole, Alkali-Aggregate Reaction in Concrete: A World Review, CRC Press (2017)

5. B Godart, M. de Rooij, J G M Wood, (Eds.) 'Guide to Diagnosis and Appraisal of AAR Damage to
Concrete in Structures', Rilem AAR 6-1 Part 1 Diagnosis, Springer, April (2013).

6. J G M Wood "When does AAR Stop?" pp 10161024. Vol II, Proc. 12th ICAAR, Beijing, (2004)

7. P. Norris et al, 'A torsion test to evaluate the deterioration of concrete due to alkali-aggregate reaction' 'Mag. of Concrete Research Vol 42 Issue 153, pp. 239-244 December (1990).

8 R Crouch, J G M Wood, 'Damage evolution in ASR affected concrete' Engineering Fracture Mechanics 35(1/2/3) 211-218 (1990).

9 T Chrisp, P Waldron, J G M Wood, 'Development of test to quantify damage in deteriorated concrete' Mag. Conc.Res 45 (165) 247- 257 (1993)

10. J G M Wood, P J Nixon, and P Livesey "Relating ASR structural damage to concrete composition and environment”. Ed. A Shayan, Proc. 10th Int Conf Alkali-Alkali Reaction in Concrete, Melbourne., (1996)

11. Concrete Society TR22 'Non-structural cracks in concrete' 4th edition (2010)

12. J G M Wood, 'Improving guidance for engineering assessment and management of structures with AAR', Proc. 13th ICAAR Trondheim, (2008).

13. B Godart, J G M Wood 'Appraising structures affected by the alkali-aggregate reaction. Proc. ICE - Construction Materials, 169, Issue 3 (2016)

14. J G M Wood, 'Enhancing Durability- Forensic Investigation of Deteriorating Structures'. Proc Int. IABSE Conference, Rotterdam, May (2013)

15. J G M Wood \& E C Angus, "Montrose Bridge:" Proc. Structural Faults - 95 Conf. London. (1995) 